\title{
Predictive capacity of self-efficacy in drug dependence and substance abuse treatment
}

\begin{abstract}
Addiction to opiates has increased in recent years. This resurgence in its consumption shows the need to continue to investigate the role of personality in addictive behavior. Variables such as self-efficacy are quite helpful in the treatment of drug addicts. The purpose of this study was to examine and quantify the predictive capacity of self-efficacy in treatment groups (Methadone, Cognitive-Behavioral, Alcohol) and a Control group and in the severity of the substance abuse (quantity and chronicity of use). The sample was composed of 181 participants (97 men and 84 women), who were divided into 4 groups: Methadone, Cognitive-behavioral, Alcohol and Control. Their self-efficacy was measured using the Self-efficacy scale (SE) and the Addictive Behavior Research Interview (EICA). The results showed the self-efficacy is inversely related to the Methadone, Cognitivebehavioral and Alcohol groups and directly related to the Control group. Regarding the severity of the drug use, we found that self-efficacy was inversely related to the quantity of drugs consumed and directly related to chronicity. The study proposes the need to evaluate self-efficacy along with other personality measures, as it is not enough to believe that one is capable of successfully doing something (self-efficacy), but it is also important to show it (coping).
\end{abstract}

Keywords: self-efficacy, dependence, drug abuse, alcohol
Volume 2 Issue 3 - 2015

\author{
Francisca Lopez Torrecillas,' Miguel Angel \\ Torres Cobo,' Pablo Delgado,' Isabel \\ Ramirez Ucles ${ }^{2}$ \\ 'Centro de Investigacion Cuerpo Cerebro Comportamiento \\ (CIMCYC), Universidad de Granada, Spain \\ ${ }^{2}$ Departamento de Psicologia Basica, Universidad Nacional de \\ Educacion a Distancia (UNED), Spain
}

\begin{abstract}
Correspondence: Francisca Lopez Torrecillas, Departamento de Personalidad, Evaluacion y Tratamiento Psicologico, Facultad de Psicologia, Campus Universitario de Cartuja s/n, Universidad de Granada, 1807I- Granada, Espana, Tel 34-95824355865405384,Email fcalopez@ugr.es
\end{abstract}

Received: January 15, 2015 | Published: March 16, 2015
Abbreviations: SE, self-efficacy; GSE, general self-efficacy; SSE, social self-efficacy

\section{Introduction}

Currently, alcohol and drugs are linked to the culture of leisure. In the past three years, a greater movement and consumption of heroin has been detected. This resurgence is no longer mainly an urban scourge, as it has extended to suburban and rural areas. The typical profiles of consumers, as occurred at its peak, are heterogeneous and show no distinctions by social class. The addiction to opiates (mainly heroin) has experienced the greatest increase among all the types of narcotics, according to the latest Worldwide Report on Drugs, elaborated by the United Nations Office against Drugs and Crime. Regarding the use of alcohol, from the latest data provided by the EDADES 2011-2012 Survey, ${ }^{2}$ we can deduce that it is the substance most consumed by Spaniards in the past twelve months.

Social learning theory, ${ }^{3}$ which recently renamed social cognitive theory, ${ }^{4}$ insists on the concept of self-efficacy as a core component of the theory and as the most important explanatory element related to the acquisition, maintenance and change in addictive behavior ${ }^{5}$. Self-efficacy refers to the belief that a person can successfully regulate his/her own behavior. Moreover, in the area of the drug addictions, the concept of self-efficacy has acquired great importance, which is mentioned in various studies, ${ }^{6-17}$ showing the role played by self-efficacy in the treatment of addictive behaviors. Additionally, drug abusers present significant alterations in extensive areas of the cortex (especially in the frontal and temporal cortex), subcortex (amygdala, hippocampus and insular cortex) and basal regions (striatum).$^{18}$ Evidence from neuro-imaging studies provided that the executive functions decline substantially with opioid use. Executive functions are higher order cognitive processes that control, integrate, organize and maintain other cognitive abilities. ${ }^{19}$ By combining neuropsychological and neuroimaging findings is has been shown that the motivational, memory and executive control processes can play a key role in rehabilitating drug addicts. These cognitive processes include the ability to concentrate, attend selectively, plan and strategize. Indeed, the self-efficacy beliefs such as prediction before performing a task and also confidence on successful results after accomplishing it, are influenced by both selection strategies and brain activity modulation. ${ }^{20}$

Specifically, one of the first studies ${ }^{12}$ investigated the perception of self-efficacy in coping with situations where it is difficult to keep from drinking, as well as the degree of alcohol dependence, in a sample of 120 subjects who were in treatment or had been in treatment six months earlier. For the evaluation, they used a questionnaire elaborated for their study and they analyzed the coping skills in high risk situations for them, the attitudes, perceptions and cognitions before and after relapses. They observed a strong relationship between avoiding risk situations, low self-efficacy and dependence on alcohol. In addition ${ }^{15}$ showed that individuals, who perceive low self-efficacy, have a limited repertoire of behaviors that are incompatible with drug use, drink too much and believe that consuming alcohol will help them to feel relaxed. Moreover, the study showed that high levels of alcohol consumption lead to lower social skills and self-efficacy. To carry out the study, the authors used a sample of 254 students who had received alcohol use prevention treatment, taking into account variables such as availability, peer pressure to consume, friends' consumption and family sanctions for consuming, which were measured at six months and two years after ending the treatment. The measure used to evaluate self-efficacy was a scale designed for this study. Along the same lines ${ }^{9}$ found that self-efficacy was related to the will to change the behavior. They evaluated self-efficacy for abstinence in the context of the stages of the change model in 224 alcoholics who were in an outpatient treatment program. The measure used was designed for this study. The authors observed that both self-efficacy for abstinence and temptations to drink were related to the subject's stage of change. Among the subjects who were in the pre-contemplation or contemplation stage, those classified as not involved or discouraged about the change had the lowest level of self-efficacy and the highest temptation levels. Another study ${ }^{6}$ also confirmed the relationship between self-efficacy 
and behaviors directed toward controlling alcohol consumption. For this purpose, they chose a sample of 118 students and measured expectations about the effects of alcohol ${ }^{17}$ and self-efficacy. ${ }^{21}$

The results show that subjects with low scores on self-efficacy, regarding the strategy of rejecting alcohol and the positive rating of the advantages of drinking (they think alcohol allows them to be more assertive, feel more relaxed and improve their sexual relations) consume more alcohol and more frequently than those who have high scores on self-efficacy and do not have these positive opinions about alcohol consumption. Another study ${ }^{16}$ was based on the hypothesis that treatment directed toward improving expectations of efficacy made it possible to increase the self-efficacy of the addicts and, consequently, maintain the abstinence longer. For their study, they chose a sample of 1,291 students, of which 142 had received treatment for their dependence and the rest took drugs but had never received treatment. They were matched on the quantity and frequency of drug use, both those who had had treatment and those who had never received it. Self-efficacy was measured ${ }^{21}$ and they found that those who had had treatment presented higher scores on self-efficacy compared to those who had not received treatment. Another study ${ }^{17}$ examined self-efficacy as a predictor of success in an outpatient treatment program to stop using marihuana. The participants in the study were 167 marihuana users in treatment. To measure self-efficacy the authors used a 19-item scale that evaluated the confidence to avoid consuming in different situations designed for this study. The results obtained revealed that self-efficacy prospectively predicted the rate of marihuana use up to one year after treatment. Later, a study was carried out ${ }^{8}$ to evaluate an instrument to measure self-efficacy. The study was designed to evaluate and validate the results of the factors measured, as well as the dimensions that made up the scale's structure. The instrument was divided into three factors: environmental, positive mood and negative mood and they analyzed it through samples with drug addicts. Selfefficacy was evaluated with a self-efficacy list for drug addicts (designed for this study) and the results showed that low self-efficacy was related to a high number of days with problems and experiences related to drug use. Other authors ${ }^{13}$ analyzed the relationship between some personality variables (self-control, assertiveness, attributional style for success, attributional style for failures and self-efficacy) and the use of drugs (quantity and chronicity of alcohol, hashish, cocaine and heroin).

Participants in the study were 53 consumers of hashish, cocaine and heroin. The measures used were the Self-control Questionnaire, ${ }^{22}$ the Attributional Style Questionnaire, ${ }^{23}$ the Assertiveness Inventory ${ }^{24}$ and the Self-efficacy Scale. ${ }^{21}$ The authors found that drug use, defined as the quantity and chronicity of the use of drugs (alcohol, hashish, cocaine and heroin), was inversely related to self-control and directly related to assertiveness. In the case of self-efficacy, they found no relationship with drug use. The authors concluded that the self-efficacy variables could be related to the use of drugs in a more complex way. Later, the same authors ${ }^{14}$ tested the relationship between self-efficacy, number of treatment attempts and chronicity of drug use (alcohol, cannabis and cocaine); to do so, they used a sample of 175 poly-consumer drug addicts (alcohol, cannabis and cocaine) who began treatment for their addiction in 44 treatment and rehabilitation centers in three districts of Bolivia: La Paz, Cochabamba and Santa Cruz. The instruments used were the Self-efficacy Scale ${ }^{21}$ and the interviews from Information about the Cultural Level and Professional Category and from Research on Addictive Behavior. ${ }^{25}$ They found that self-efficacy predicted the chronicity of the use of alcohol, cannabis and cocaine. More recently, two studies were carried out ${ }^{11}$ to investigate the effects of the influence of parents and classmates, publicity and self-efficacy in alcohol and tobacco use in adolescents. In the first study, the participants were
101 adolescents who presented risk behaviors in relation to smoking. To evaluate the influence of publicity, they were asked the following questions: "In the past month, how many cigarette commercials do you remember seeing in the news media?"; "In the past month, how many cigarette commercials do you remember seeing in the media?" and "In general, what is your attitude toward what you see in cigarette commercials?" To evaluate the influence of parents and classmates, they were asked the following questions: "How often do your parents (your classmates) smoke cigarettes?"; "What is your parents' (your classmates') general attitude toward smoking cigarettes?" and "How often do you feel you have to accept the attitude of your parents (your classmates) toward smoking cigarettes?" The questions were responded to on a scale from 1 to 5 . To evaluate self-efficacy, the authors used the Self-efficacy Scale. ${ }^{21}$

In the second study, 89 adolescents participated who presented risk behaviors in relation to smoking and alcohol. To carry out the evaluation, the same procedure was used as in study 1 , but the term "cigarettes" was substituted by the words "beer, wine and/or alcohol". The results obtained suggest that: the effects of publicity are greatly neutralized by the influence of parents and classmates; this social influence predicts both the use of both tobacco and alcohol; and selfefficacy is a predictor of risk behaviors in adolescents. Moreover, one study ${ }^{10}$ investigated the influence of the therapeutic alliance and self-efficacy on changes in alcohol consumption and psychological functioning in a group of alcoholics after treatment and during a oneyear follow-up. In the study, participants were 1,383 patients who received treatment for 16 weeks and a one-year follow-up. They were divided into three groups: group 1 only received pharmacological treatment $(\mathrm{n}=607)(\mathrm{MM})$, group 2 received pharmacological treatment and behavioral intervention $(\mathrm{CBI})(\mathrm{n}=619)$ and group 3 was the control group $(n=157)$. The participants filled out the Alcohol Dependence Scale $;{ }^{26}$ the Drinking Consequences Inventory; ${ }^{27}$ the Therapeutic Alliance Inventory; ${ }^{28}$ the Brief Symptom Inventory, ${ }^{29}$ which evaluates the perception of depressive, anxiety, somatization and psychoticism symptoms and the Alcohol Abstinence Self-efficacy Scale,$^{30}$ which determines the alcoholic's confidence about abstaining from alcohol in high risk situations using the score on a 5-point scale ( $1=$ nothing, $5=$ extremely $)$ and contains subscales on negative effect, positive /social, physical concerns and withdrawal/urges. The results indicate that self-efficacy intervenes in the treatment results in groups 1 and 2, but not in the control group. Finally, a more recent study ${ }^{7}$ analyzed the relationship between self-efficacy (a person's belief that he/she can refrain from consuming cannabis) and the expectations of the result (perceived consequences of consuming cannabis) in a sample of 1,115 cannabis users in treatment. The measures used were the Cannabis Expectations Questionnaire ${ }^{31}$ and the Cannabis Rejection Self-efficacy Questionnaire..$^{32}$ The authors found a negative relationship between self-efficacy, cannabis consumption and their effects.

The belief that one is capable of successfully reaching a goal influences the treatment result and remaining abstinent from consuming drugs because it favors active participation in the treatment, adequately coping with the problem, effort and persistence. By contrast, the belief that one is not capable of successfully reaching a goal interferes with trying to stop consuming these substances and leads to their use or to relapse. Therefore, we can conclude that selfefficacy is inversely related to drug use and directly to a positive treatment outcome. However, there are no studies that compare the level of self-efficacy in drug addicts depending on the substance consumed (heroin, cocaine, cannabis, alcohol, etc.), or studies that relate the level of self-efficacy to the severity of the drug use (quantity and chronicity of alcohol and drug use). 
Therefore, the purpose of this study is to examine and quantify the predictive capacity of self-efficacy on the groups (Methadone, Cognitive-behavioral, Alcohol and Control) and on the severity of the drug use (quantity and chronicity of consumption). Based on these objectives, we can specify the following hypotheses:

i. The self-efficacy scores will be inversely related to the severity of the drug use (quantity and chronicity of consumption).

ii. The self-efficacy scores predict the treatment groups, inversely in the Methadone group and directly in the Cognitive-behavioral treatment and Alcohol groups.

iii. Differences are expected in the prediction of self-efficacy between the treatment groups (Methadone, Cognitive-behavioral and Alcohol) and the Control group.

\section{Method}

\section{Participants}

The study was composed of 181 participants ( 97 men and 84 women) divided into 4 groups. In the case of the first three groups, the selection was carried out in the Granada Regional Drug Addiction Center and the first inclusion criterion was to be receiving treatment for drug addiction, having passed through the phase of detoxification and being in the de-habituation phase. Specifically, the group 1 drug addicts in Methadone Treatment $(\mathrm{n}=46)$ considered heroin to be the problem drug. The inclusion criteria in this group were having a prior history of abuse of multiple substances intravenously and repeated therapeutic failures, being in treatment with methadone and having consumed hashish, cocaine, amphetamines, heroin, hallucinogens and/or alcohol. Group 2, drug addicts in Cognitivebehavioral Treatment $(\mathrm{n}=45)$, also considered heroin to be the problem drug and the inclusion criteria were having a prior history of abuse of multiple substances intravenously, not having previously been in drug addiction treatment, having family and social support and a high motivation for abstinence, being in cognitive-behavioral treatment for drug addiction and having consumed hashish, cocaine, heroin, methadone, hallucinogens and alcohol. Group 3, Alcoholics in Treatment $(\mathrm{n}=52)$, considered their drug problem to be alcohol and the inclusion criteria were not consuming any other substance, being in treatment for alcoholism and presenting socio-demographic characteristics similar to the participants in groups 1 and 2. Group 4, the Control Group $(\mathrm{n}=38)$ was recruited from the general population through advertisements. The inclusion criteria were not consuming any substance and presenting socio-demographic characteristics similar to those of the participants in groups 1, 2 and 3. In all the groups, the exclusion criteria did not want to voluntarily participate in the study, not correctly filling out the questionnaires, inventories and evaluation scales, presenting serious psychopathological or organic disorders, or being pregnant in the case of women. The sociodemographic characteristics can be seen in Table 1.

Table I Socio-demographic characteristics of the groups

\begin{tabular}{|c|c|c|c|c|c|c|c|}
\hline \multirow[t]{2}{*}{ Variables } & \multirow[t]{2}{*}{ Categories } & \multicolumn{6}{|l|}{ Groups } \\
\hline & & Methadone & Alcohol & Cognitive-Behavioral & Control & $\chi^{2}$ & $\mathbf{p}$ \\
\hline \multirow[t]{2}{*}{$\operatorname{Sex}(N)$} & Man & 23 & 27 & 26 & 21 & & \\
\hline & Women & 23 & 18 & 26 & 17 & & \\
\hline \multirow{3}{*}{$\begin{array}{l}\text { Years of } \\
\text { education }(\mathrm{N})\end{array}$} & Primary & 39 & 15 & 33 & 13 & 50.1 & 0 \\
\hline & Secondary & 4 & 28 & 19 & 16 & & \\
\hline & Degree/License & 3 & 2 & 0 & 9 & & \\
\hline \multirow[t]{9}{*}{ Profession $(\mathrm{N})$} & Not work & 9 & 8 & 20 & 8 & 79 & 0 \\
\hline & Higher degree & 0 & 0 & 0 & I & & \\
\hline & Office work & 3 & 2 & 8 & I & & \\
\hline & Business & 0 & 7 & 4 & 6 & & \\
\hline & Hospitality & 0 & 4 & 5 & 14 & & \\
\hline & Agriculture and Farming & 8 & 9 & 7 & 0 & & \\
\hline & Construction & 12 & 10 & 7 & 0 & & \\
\hline & Plumbing/Carpentry/Painting & 14 & 5 & 1 & 8 & & \\
\hline & & & & & & $\mathrm{F}$ & $P$ \\
\hline Age & Mean (SD) & 31.78 (4.63) & $30.29(4.19)$ & $31.19(5.15)$ & $30.90(7.63)$ & 0.59 & 0.6 \\
\hline
\end{tabular}

Table 2 Characteristics of the groups

\begin{tabular}{|c|c|c|c|c|c|c|c|}
\hline \multirow[t]{2}{*}{ Variables } & \multirow[t]{2}{*}{ Categories } & \multicolumn{3}{|l|}{ Groups } & & \multicolumn{2}{|c|}{ Total } \\
\hline & & Methadone & Alcohol & Cognitive-Behavioral & Control & & \\
\hline \multirow[t]{4}{*}{ Self-efficacy } & $<70$ & 33 & 32 & 50 & 14 & 129 & \\
\hline & $>90$ & 13 & 13 & 2 & 24 & 52 & \\
\hline & Total & 46 & 45 & 52 & 38 & 181 & \\
\hline & & & & & & $\mathrm{F}$ & $\mathrm{P}$ \\
\hline Quantity & Mean and (SD) & $.54(.58)$ & $.20(.43)$ & $1.36(.72)$ & $.00(.00)$ & 33.9 & 0 \\
\hline Chronicity & Mean and (SD) & $.64(.59)$ & $.03(.39)$ & $-.32(.18)$ & $.00(.00)$ & 45.9 & 0 \\
\hline
\end{tabular}




\section{Measures}

\section{The following measures were used:}

Self-efficacy scale: ${ }^{24}$ This scale was developed by analyzing the personal beliefs about their ability to cope with certain situations. The scale is composed of 30 items that measure overall self-efficacy (TSE), divided into 2 subscales. The general self-efficacy subscale (GSE) describes dealing with situations related to personal tasks and the social self-efficacy subscale (SSE) describes coping with social situations. On both scales, the participant must indicate the degree to which a sentence describes or characterizes him/her on a scale from 1 to 5 . The scale also has 7 filler items. A high score (above 90) on this scale indicates high levels of self-efficacy, while a low score (below 70) indicates low self-efficacy. The scale has been adapted and validated in the Spanish population. ${ }^{33}$

Addictive behavior research interview: ${ }^{25}$ This scale deals with the addictive behavior, particularly the abuse of alcohol, hashish, methadone, hallucinogens, cocaine and heroin. It refers to the frequency of use of these substances, the quantity consumed and the age of initiation in their use. The scale consists of 7 items divided into three groups of questions, one group about the quantity (frequency), a second group about the quantity (grams, milliliters or units) and a third group about chronicity (years since beginning the drug use). Each item reflects the pattern of consumption of a certain drug. The drugs named in the questionnaire are alcohol, hashish, hallucinogens, cocaine and heroin. Subjects are asked to describe their history of drug use. Each of the drugs for which information is requested is rated according to the frequency of use or the quantity of the substance consumed, on a scale from 1 to 8 , ranging from never to daily. The second group of questions also refers to the quantity consumed, scored in units per month, taking into account that a glass of whiskey equals one unit and a glass of wine or beer equals 0.5 , hashish is scored by the number of cigarettes, amphetamines and hallucinogens are scored in units, methadone is scored in milligrams and cocaine and heroin in grams per month. The third group of questions has to do with the chronicity or years consuming the substance and it is scored according to the number of years from beginning to use the substance until the time of the evaluation. Based on this questionnaire, 14 measures are obtained that report on the quantity of consumption in terms of the frequency of the drug use and the quantity consumed in the past month (amount of alcohol, hashish, amphetamines, methadone, hallucinogens, cocaine and heroin), as well as the chronicity or years since beginning the drug use (chronicity of alcohol, hashish, amphetamines, methadone, hallucinogens, cocaine and heroin). A total score is also obtained by adding the 14 standardized measures together and this score is considered the level of severity of the drug abuse.

\section{Procedure}

Before beginning the study, a member of the therapeutic team responsible for recruiting the participants in groups 1,2 and 3 was in charge of explaining the study and inviting each patient to participate in it. All the participants who began the treatment in the Regional Center of Granada were invited to participate in a prospective study to evaluate self-efficacy in relation to methadone, cognitive-behavioral and alcohol treatment. The participants provided informed consent met the inclusion and exclusion criteria and were programmed for an initial evaluation before the beginning of the dishabituation phase and once the detoxification phase had ended. Once the person had agreed to participate, he or she signed the informed consent. Thus, the participant was sent to the clinical researcher, who made an appointment to carry out the entire evaluation process in the same day. The control group was recruited through verbal and written advertisements in recreational centers and schools for adults in the metropolitan area of Granada. The mean length of the evaluation was approximately 30 minutes.

\section{Statistical analyses}

The survival analysis was conducted with the SPSS software package. The predictor variable (Self-efficacy) was dichotomized: low scores were less than or equal to 70 and high scores were greater than or equal to 90 . A contingency table was made to present the number of participants included in each group (Methadone, Cognitive-behavioral, Alcohol and Control) with high and low scores on Self-efficacy. Moreover, in order to discover the differences between the groups on drug use severity, two ANOVAs were conducted for a between-groups unifactorial design using the variable group (Methadone, Cognitivebehavioral, Alcohol and Control) as the factor and the total scores for quantity and chronicity of drug use as dependent variables. Finally in order to examine and quantify the predictive capacity of self-efficacy on the groups (Methadone, Cognitive-behavioral, Alcohol and Control) and the drug use severity (quantity and chronicity of drug use), binary logistic regression analyses were carried out following the backward stepwise regression procedure based on the Wald statistic.

The logistic regression model estimates the probability of an event, incident or result occurring (Methadone, Cognitive-behavioral, Alcohol, Control and quantity and chronicity of drug use) in the presence of one or more predictors (high or low self-efficacy scores). This probability is estimated by means of the odd ratio (OR) statistic. If the $\mathrm{OR}$ is greater than one, the increase in the independent variable is associated with an increase in the advantage of the event. If, on the other hand, the OR is less than one, the increase in the independent variable is related to a reduction in the advantage of the event.

\section{Results}

Table 2 shows the number of participants that make up the groups (Methadone, Cognitive-behavioral, Alcohol and Control) regarding their high and low scores on self-efficacy. The table also presents the means and standard deviations of the drug use severity (quantity and chronicity) of the groups (Methadone, Cognitive-behavioral, Alcohol and Control) and their level of significance.

Two binary logistic regression analyses were performed to examine the predictive capacity of self-efficacy on the groups and the drug use severity (quantity and chronicity of drug use). Table 3 shows that the groups (Methadone, Cognitive-behavioral, Alcohol and Control) and the drug use severity (quantity and chronicity of drug use) are significant. The negative sign of the beta coefficient (B) indicates the direction of the relationship; that is, self-efficacy is inversely related to the Methadone, Cognitive-behavioral and Alcohol groups and directly to the Control group. Therefore, the inverse relationship between the Methadone, Cognitive-behavioral and Alcohol groups and self-efficacy indicates that, as self-efficacy increases, the probability of belonging to the Methadone, Cognitivebehavioral and Alcohol group's decreases by 1.471, 1.44 and 3.758, respectively. The Control group is directly related to self-efficacy; therefore, as self-efficacy increases, the probability of remaining in the Control Group increases by 1.952 .

Regarding drug use severity, we find that the quantity consumed presents an inverse relationship with self-efficacy, indicating that as self-efficacy increases, the probability of consuming is reduced by 0.004 , while the chronicity of the drug use presents a direct 
relationship with self-efficacy, so that as self-efficacy increases, the time of consumption increases by 0.018 (Table 3 ).

Table 4 shows the percentage of correct classification in the groups

Table 3 Results derived from the Regression Analysis

\begin{tabular}{lllllll} 
Factor & B & E.T & Wald & P & OR & IC 95\% \\
\hline Methadone Group & $-1.47 I$ & 0.469 & 9.815 & 0.002 & 0.23 & $.092-.577$ \\
Cognitive-Behavioral Group & -1.44 & 0.47 & 9.369 & 0.002 & 0.237 & $.094-.596$ \\
Alcohol Group & -3.758 & 0.796 & 22.306 & 0 & 0.023 & $.005-.11$ I \\
Control & 1.952 & 0.397 & 24.185 & 0 & 7.041 & $3.235-15.326$ \\
Constant & 0.539 & 0.336 & 2.569 & 0.109 & 1.714 & \\
Quantity & -0.004 & 0.002 & 5.634 & 0.018 & 0.996 & $.992-.999$ \\
Chronicity & 0.018 & 0.007 & 6.122 & 0.013 & 1.018 & $1.004-1.033$ \\
Constant & -0.663 & 0.226 & 8.609 & 0.003 & 0.515 &
\end{tabular}

$\mathrm{B}=$ Coefficient ET = Standard Error $; \mathrm{P}=$ Probability; OR = Odd Ratio; IC = Confidence Interval at $95 \%$
Table 4 Percentage of classification

\begin{tabular}{lll}
\hline Self-efficacy & Groups & $\%$ Classification \\
\hline & $<70$ & 89.1 \\
& $>90$ & 46.2 \\
& Total & 76.8 \\
& Severity: Quantity and Chronicity of Drug Use \\
& $<70$ & 98.4 \\
& $>90$ & 13.5 \\
& Total & 74 \\
\hline
\end{tabular}

\section{Discussion}

The purpose of this study was to examine and quantify the predictive capacity of self-efficacy on the groups (Methadone, Cognitive-behavioral, Alcohol and Control) and the severity of the drug use (quantity and chronicity of use).

Regarding our first hypothesis, we obtained significant differences in the levels of self-efficacy among the different groups, especially between the Cognitive-behavioral and Control groups. In the Cognitive-behavioral group there were a high number of participants with low self-efficacy, which indicates that the level of self-efficacy is not a criterion used in Treatment Centers to assign patients to different treatment groups. Self-efficacy levels are likely to increase as the treatment progresses, as shown by other studies, ${ }^{6,9,16}$ which point out that self-efficacy increases during treatment and that it is related to behaviors directed toward controlling alcohol consumption and the will to change behaviors.

Regarding the second hypothesis, we found that self-efficacy was inversely related to the Methadone, Cognitive-behavioral and Alcohol groups and directly to the Control group. Specifically, the results showed that as self-efficacy increases, the probability of remaining in the Methadone, Cognitive-behavioral and Alcohol group's declines by $1.471,1.44$ and 3.758 , respectively. The Control group is directly related to self-efficacy. Therefore, as self-efficacy increases, the probability of remaining in the Control group increases by 1.952 . These results agree with those obtained in other studies ${ }^{10,11,17}$ that conclude that self-efficacy is a good predictor of drug addictions and risk behaviors in adolescents, although this relationship can be complex. ${ }^{13}$ efficacy would be inversely related to drug use severity (quantity and chronicity of use). Regarding the quantity of drugs consumed, the results reveal an inverse relationship with self-efficacy, indicating that
Finally, our third hypothesis proposed that the scores on self-
(Methadone, Cognitive-behavioral, Alcohol and Control) and in the drug use severity (quantity and chronicity of drug use) for the high and low scores on self-efficacy. For the groups, the percentage of total correct classification was $76.8 \%$ and for drug use severity was $74 \%$. by 0.004 . However, the chronicity of drug use presents a direct relationship with self-efficacy, so that as self-efficacy increases, time of consumption increases by 0.018 . These results coincide with those obtained by other studies ${ }^{7,14}$ that showed the relationship between selfefficacy and the quantity and chronicity of drug use.

It is important to highlight the results obtained in relation to selfefficacy and the quantity and chronicity of drug use. A smaller quantity of drug consumed corresponded to a longer consumption time and higher levels of self-efficacy. However, these results do not contradict those obtained in the literature reviewed, ${ }^{6,9,12}$ which indicates that self-efficacy is related to the will to change behavior and the degree of drug dependence. It seems logical that a person who believes that he/she has control over his/her behavior will delay the decision to modify this behavior. Thus, there is a direct relationship between selfefficacy and the chronicity of the drug use. It is also logical to suppose that self-efficacy is directly related to self-control, that is the greater the self-efficacy and/or self-control, the lower the quantity of drugs consumed.

Therefore, our results point to the idea of the level of complexity of the self-efficacy variable and they lead us to pose a series of questions: Is self-efficacy a risk factor in maintaining a controlled use of drugs? Is there a cut-off point at which very high or very low scores are not adequate and lead to performing risky behaviors for health?. While we empirically answer these questions, it would also be advantageous to evaluate coping skills. It is not only important to believe that one is capable of successfully reaching a goal (self-efficacy: preintention), but it is also necessary to demonstrate it (coping: postintention).

Among the main limitations of this study is the low number of participants, which means it should be replicated with a larger sample. In addition, it would be interesting to analyzing other personality variables, such as self-control or impulsivity, in order to obtain a more global view of the results. In spite of its limitations, the interest of our study lies especially in the fact that we compared treatment groups with a control group. In the literature reviewed, only one study ${ }^{10}$ also uses a control group. It remains to be determined whether changes in executive functions and in self-efficacy are dependently associated with abstinence and prognosis of treatment. Such knowledge would facilitate the development and refinement of targeted interventions to improve the treatment in drug addiction. Thus, we think it is a relevant topic that should be investigated more in-depth in future studies. 


\section{Acknowledgments}

None.

\section{Conflicts of interest}

Author declares there are no conflicts of interest.

\section{Funding}

None.

\section{References}

1. United Nations Office on Drugs and Crime (UNODC). Informe mundial sobre las drogas. United Nations Office on Drugs and Crime. 2014.

2. Delegacion del Gobierno para el Plan Nacional sobre Drogas. Encuesta sobre alcohol y drogas en poblacion general en Espana. Delegacion del Gobierno para el Plan Nacional sobre. 2011.

3. Bandura A. Principles of behavior modification. Holt, Rinehart \& Winston, New York, USA. 1969. p.677.

4. Bandura A.Social foundations of thought and action: A Social Cognitive Theory. Prentice-Hall, Englewood Cliffs. 1986.

5. Bandura A. Self-efficacy in changing societies. Cambridge University Press, USA. 1995.

6. Baldwing AR, Oei TPS, Young R. To drink or not to drink: the differential role of alcohol expectancies and drinking refusal self-efficacy in quartely and frequency of alcohol consumption. Cog. Therapy Res. 1993; 17:511-530.

7. Connor JP, Gullo MJ, Feeney GF, et al. The relationship between cannabis outcome expectancies and cannabis refusal self-efficacy in a treatment population. Addiction. 2014;109(1):111-119.

8. De Weert Van Oene GH, Breteler MH, Schippers GM, et al. The validity of the Self-Efficacy List for Drug Users (SELD). Addict Behav. 2000;25(4):599-605.

9. DiClemente CC, Hughes SO. Stages of change profiles in outpatient alcoholism treatment. $J$ Subst Abuse. 1990;2(2):217-235.

10. Hartzler B, Witkiewitz K, Villarroel N, et al. Self-efficacy change as a mediator of associations between therapeutic bond and one-year outcomes in treatments for alcohol dependence. Psychol Addict Behav. 2011;25(2):269-278.

11. Kinard BR, Webster C. The effects of advertising, social influences, and self-efficacy on adolescent tobacco use and alcohol consumption. $J$ Consum Aff. 2010;44(1):24-43.

12. Litman GK, Eiser JR, Rawson NS, et al. Towards a typology of relapse: a preliminary report. Drug Alcohol Depend. 1977;2(3):157-162.

13. Torrecillas FL, Peralta I, Rivas MM, et al. Autocontrol y consumo de drogas. Adicciones. 2003;15(2):127-136.

14. Torrecillas FL, Caballo V, Pastor Del Carpio L, et al. La eficacia general como predictora de la cronicidad del consumo de drogas. Psicologia Conductual. 2005;13(2):289-296.

15. Pentz MA. Coping and substance use: A conceptual framework. In: Shiffman S \& Wills TA (Eds.). Coping and substance use. Academic Press, Nueva York. 1985. p.117-139.
16. Sadowski CJ, Long CK, Jenkins LR. Does substance abuse treatment have self-schematic effects? J Psychol. 1993;127(3):323-327.

17. Young RMcD, Oei TPS, Crook CM. Development of a Drinking Self Efficacy questionnaire. Journal of Psychopathology and Behavioral Assessment. 1991;13(1):1-15.

18. Verdejo GA, Perez GM, Sanchez BM, et al. Neuroimaging and drug addiction: neuroanatomical correlates of cocaine, opiates, cannabis and ecstasy abuse. Rev Neurol. 2007;44(7):432-439.

19. Thal DR, Del Tredici K, Braak H. Neurodegeneration in normal brain aging and disease. Sci Aging Knowledge Environ. 2004;2004(23):pe26.

20. Chua EF, Schacter DL, Rand Giovannetti E, et al. Understanding metamemory: Neural correlates of the cognitive process and subjective level of confidence in recognition memory. Neuroimage. 2006;29(4):1150-1160.

21. Sherer M, Maddux JE, Mercandante B, et al. The Self- efficacy Scale: Construction and validation. Psychological Reports. 1982;51:663-671.

22. Rosenbaum M. Cuestionario de autocontrol. In: A Capafons \& P Barreto (1989) (traduccion y adaptacion). Competencia aprendida: Fiabilidad y validez de su medida, criticas y recomendaciones. Revista Espanola Terapia Comp. 1980;1:19-39.

23. Peterson C, Semmel A, Von Baeyer C, et al. The attributional style questionnaiere. Cog Therapy Res. 1982;6(3):287-299.

24. Rathus SA. Escala de asertividad. In: Bartolome P et al. (Eds.), La practica de la terapia de conducta. Madrid: Pablo del Rio (Apendice). 1973.

25. Lopez-Torrecillas F. Estres, afrontamiento, variables de personalidad y consumo de drogas. Universidad de Granada, Granada. 1996.

26. Skinner HA, Allen BA. Alcohol dependence syndrome: Measurement and validation. J Abnorm Psychol. 1982;91(3):199-209.

27. Miller WR, Tonigan JS, Longabaugh R. The Drinker Inventory of Consequences (DrInC): An Instrument for Assessing Adverse Consequences of Alcohol Abuse. Project MATCH Monograph Series, NIAAA. 1995;4(95):3911.

28. Horvath AO, Greenberg LS. Development and validation of the Working Alliance Inventory. J Couns Psychol. 1989;36(2):223-233.

29. Derogatis LR. Brief symptom inventory: Administration, scoring, and procedures manual. National Computer Systems; Minneapolis. 1993.

30. DiClemente CC, Carbonari JP, Montgomery RP, et al. The Alcohol Abstinence Self-Efficacy scale. J Stud Alcohol. 1994;55(2):141-148.

31. Connor JP, Gullo MJ, Feeney GF, et al. Validation of the Cannabis Expectancy Questionnaire (CEQ) in adult cannabis users in treatment. Drug Alcohol Depend. 2011;115(3):167-174.

32. Young RM, Gullo MJ, Feeney GF, et al. Development and validation of the cannabis refusal self-efficacy questionnaire (CRSEQ) in adult cannabis users in treatment. Drug Alcohol Depend. 2012;125(3):244-251.

33. Lopez Torrecillas F, Garcia J, Canadas GA, et al. Validity of self-efficacy scale scores for a Spanish sample. Psychol Rep. 2006;98(2):437-450. 